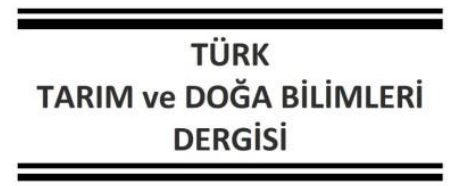

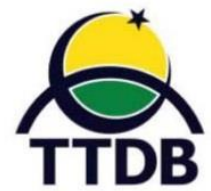

www.dergipark.gov.tr/turkjans Araştırma Makalesi

\title{
Çanakkale ilinde Çeltik Üretiminin Ekonometrik Analizi
}

\author{
Arif SEMERCi ${ }^{1 *}$, Bengü EVEREST ${ }^{1}$ \\ ${ }^{1}$ Çanakkale Onsekiz Mart Üniversitesi, Ziraat Fakültesi, Tarım Ekonomisi Bölümü, Çanakkale \\ *Sorumlu Yazar: arifsemerci@comu.edu.tr
}

Geliş Tarihi: 06.10.2020 Düzeltme Geliş Tarihi: 27.04.2021 Kabul Tarihi: 29.06.2021

$\overline{\text { Öz }}$

2018-2019 üretim dönemi IGC verilerine göre dünya çeltik üretim alanları 163 milyon ha, üretim miktarı ise 745 milyon ton olarak gerçekleşmiştir. Aynı dönemde dünya pirinç üretimi ise 500 milyon ton olmuştur. Türkiye'nin ekim alanlarındaki payı \%0.07, üretim miktarındaki payı ise $\% 0.12$ olup pirinçte kendine yeterlilik oranı \%80'dir. 2019 yılı Tüik verilerine göre Türkiye'de çeltik üretim alanı 126,419 ha, üretim miktarı ise 1,000,000 ton olarak gerçekleşmiştir. Çanakkale ili ülke genelinde çeltik ekim alanlarından aldığı \%8.72 ve üretim miktarındaki \%9.30 pay ile 4. sırada yer almaktadır. İlde ortalama çeltik verimi $8438.30 \mathrm{~kg} \mathrm{~h}^{-1}$ olup, ülke verim değerinin $\left(7910,20 \mathrm{~kg} \mathrm{ha}^{-1}\right)$ üzerindedir. Yapılan çalışmada çeltik üretimine ilişkin oluşturulan üretim fonksiyonunda; tohum masrafı $\left(X_{1}\right)$ gübre masrafı $\left(X_{3}\right)$, tarımsal mücadele ilacı masrafı $\left(X_{4}\right)$ ve mazot masrafına $\left(X_{5}\right)$ ilişkin girdilerinin üretim elastikiyetleri \%5 ihtimal düzeyinde önemli bulunmuş, denklemin üretim elastikiyetleri katsayıları toplamının $\left(\Sigma \beta_{i}: 1.002\right)$ ise ölçeğe artan getiriyi ifade ettiği sonucuna varılmıştır. Oluşturulan denklemde yer alan faktörler arasında marjinal etkinlik katsayısı en yüksek değişken tarımsal mücadele ilacı masrafı $\left(X_{2}\right)$ olarak bulunmuştur. Çalışmada çeltik üretiminde marjinal teknik ikame oranlarına göre tohum $\left(X_{1}\right)$ faktörünün mazot faktörüne $\left(X_{5}\right)$ oranla ekonomik optimuma en yakın düzeyde kullanılan girdi bileşenleri olduğu anlaşılmıştır.

Anahtar kelimeler: Çeltik, Ekonometrik analiz, Cobb-Douglas, Çanakkale.

\section{Econometric Analysis of Paddy Production in Çanakkale Province}

\begin{abstract}
According to IGC data for 2018-2019 production period, global paddy production area size was 163 million ha, and global production amount was 745 million tons. In the same period, world rice production was 500 million tons.Turkey's proportion for production area was $0.07 \%$, it was $0.12 \%$ in paddy production amount, and Turkey's self-sufficiency rate for rice was $80 \%$. According to TSI data for 2019, Turkey's paddy production area size was 126,419 ha, and production amount was 1,000,000 tons. Çanakkale City, takes $8.72 \%$ of Turkey's paddy production area, and it is the $4^{\text {th }}$ city in terms of production amount with a proportion of $9.30 \%$. Çanakkale province's yield average in paddy is $8438,30 \mathrm{~kg} \mathrm{ha}^{-1}$ that is higher than Turkey's average $(7910,20 \mathrm{~kg}$ $\left.\mathrm{ha}^{-1}\right)$. The mathematical function variables of paddy production were as followed; seed cost $\left(\mathrm{X}_{1}\right)$, fertilizer cost $\left(X_{3}\right)$, pesticide cost $\left(X_{4}\right)$ and diesel fuel cost $\left(X_{5}\right)$, and production elasticities of inputs were found statistically significant at the level of $5 \%$ error margin, and coefficient total of production elasticities $\left(\sum \beta_{i}: 1.002\right)$ indicates that increasing returns to scale. Among the variables of the equation, pesticide cost $\left(\mathrm{X}_{4}\right)$ has the highest marginal efficiency. According to technical substitution rate, diesel fuel factor $\left(X_{5}\right)$ proportion to seed factor $\left(X_{1}\right)$ was found the closest input components to economic optimum.
\end{abstract}

Key words: Paddy, Econometric Analysis, Cobb-Douglas, Çanakkale. 


\section{Giriş}

Pirinç, insan beslenmesinde önemli bir yer tutan tarım ürünlerinden biridir. Dünya pirinç üretimi 2018/19 döneminde 500,000,000 ton seviyesine ulaşmış olup, üretimin $\% 73.06$ 'sı başta Çin olmak üzere, Hindistan, Endonezya, Bangladeş ve Vietnam tarafından karşılamaktadır (IGC, 2020). Türkiye'de 2000'li yılların başından itibaren uygulanmaya başlanan tarımsal destekleme politikaları yanında, üretimde kaliteli ve yüksek verimli çeltik tohumlarının kullanılması ve çeltik üreticisinin modern tarım yöntemlerinin kullanmasıyla ülkede çeltik üretiminde önemli derecede artış görülmüştür. Türkiye'de 2002-2016 yılları arasında çeltik ekim alanı \%93.46, çeltik üretimi \%155.56 oranında artış göstermiştir. Aynı dönemde verim değerindeki artış miktarı ise $193 \mathrm{~kg}$ da $^{-1}$ olmuştur (TÜiK, 2019). Türkiye'de pirinç tüketimi 2019 yılında 750,000 ton seviyelerinde olmasına rağmen üretim 600,000 ton olup, arz açığı olan 150,000 ton ithalatla karşılanmaktadır. 2002 yılında pirinç tüketiminde arzın talebi karşılama oranı \%38 düzeyinde iken bu oran 2019 yılında \%80 düzeyine yükselmiştir (TOB, 2020).

2019 yılı TÜik verilerine göre Türkiye'de çeltik üretim alanı 1,264,190 da, üretim miktarı ise $1,000,000$ ton olarak gerçekleşmiştir. Çanakkale ilinin ülke çeltik ekim alanlarındaki payı \%8.72, üretim miktarındaki payı ise \%9.30'dur. İlde çeltik verimi $843.83 \mathrm{~kg} \mathrm{da}^{-1}$ olup, ülke verim değerinin (791.02 kg da-1) üzerindedir.

Konu ile ilgili olarak yapılan çalışmalar incelendiğinde Türkiye'de çeltik üretiminin fonksiyonel analizine dayalı çalışmaların neredeyse yok denecek kadar az olduğu anlaşılmaktadır (Semerci, 1998). Dünya genelinde ise özelikle üretimin yoğun olduğu Uzakdoğu Asya ülkelerinde çeltik üretiminin ekonomik ve fonksiyonel analizine dayalı çalışmalar yoğun olarak yapılmaktadır (Sikdar ve ark., 2008; Hile ve ark., 2015; Kaka ve ark., 2016; Siagian, 2019). Çeltik ürününe yönelik olarak yapılan çalışmalar daha ziyade ürünün maliyeti ve pazarlanması konularında yoğunlaşmaktadır (Öztürk ve Akçay, 2010). Bazı çalışmalarda ise pirinç üretimi ve dış ticareti ayrıntılı olarak incelenmiştir (Çelik ve ark., 2018; Semerci ve ark., 2019). Hem genel hem de işletme bazında çeltik üreten işletmelerin bu ürüne yönelik destekleme politikalarına yönelik bakış açılarını ortaya koyan çalışmalar da özel önem arz etmektedir (Kudal, 2019). Bununla birlikte dünyada ve Türkiye'de çeltiğin genel görünümüne yönelik olarak hazırlanan bazı raporlar da bulunmaktadır (TOB, 2019).

Yapılan bu araştırma ile Çanakkale ilinde faaliyet gösteren tarım işletmelerinde çeltik üretim miktarı ile üretimde kullanılan girdilerin ilişki düzeyleri Cobb-Douglas üretim fonksiyonu kullanılarak incelenmiş, araştırma bulguları diğer araştırma sonuçlarıyla karşılaştırılarak yorumlanmıştır.

\section{Materyal ve Metot}

Araştırmanın birincil verilerini Çanakkale ilinde çeltik üreten tarım işletmelerinden derlenen veriler oluşturmaktadır. Araştırma kapsamında 2019 yılı Ocak-Şubat döneminde yüzyüze anket uygulamaları yapılmıştır. Araştırmanın ikincil verileri ise; Birleşmiş Milletler Gıda ve Tarım Örgütü (FAO), Tarım ve Orman Bakanlığı (TOB) ile Türkiye İstatistik Kurumu (TÜIK) tarafından yayınlanan verileri kapsamaktadır.

\section{Örnekleme yöntemi}

Araştırmada uygulanan anket sayısının belirlenmesinde Neyman tarafından önerilen formülden yararlanılmıştır (Yamane, 2010).

$$
\boldsymbol{n}=\frac{\mathbf{\Sigma}(N h S h)^{2}}{N^{2} D^{2}+\mathbf{\Sigma} N h(S h)^{2}}
$$

Formülde;

$\mathrm{n}=$ Örnek Hacmi

$\mathrm{Nh}=h^{\prime} ı$ cı tabakadaki işletme sayısı

$\mathrm{Sh}=\mathrm{h}^{\prime} ı \mathrm{nc}$ t tabakanın standart sapması

$\mathrm{N}=$ Örnekleme çerçevesine ait toplam işletme sayısı

$D=$ Kabul edilebilir hata payı $(d / z)$

$\mathrm{d}=$ Ortalamadan belirli bir düzeydeki sapma

$\mathrm{z}=\mathrm{t}$ Dağılım çizelgesinde ( $\mathrm{N}-1)$ serbestlik derecesi ve belirli bir güven sınırına ait " $t$ " değeri.

Örnekleme çerçevesine girecek çeltik üretem işletme sayılarının belirlenmesinde Çanakkale II Tarım ve Orman Müdürlüğü 2018 yılı Çiftçi Kayıt Sistemi (ÇKS) verilerinden yararlanılmıştır. Aynı yılın verilerine göre il genelinde 865 tarım işletmesinde 65,000 da alanda çeltik üretimi yapıldığı anlaşımaktadır. Araştırma kapsamında \%99 güven aralığı ve \%5 ortalamadan sapma ile tespit edilen 74 tarım işletmesinde anket uygulaması gerçekleştirilmiştir.

Çalışmada çeltik üretim miktarı ile üretimde kullanılan girdiler arasındaki ilişkilerin belirlenmesinde "Cobb-Douglas Tipi Fonksiyon" kullanılmıştır (Zoral,1984). Marjinal analizlerde, işletmelerin ortalama çeltik satış fiyatı, işgücü için yabancı işgücüne ödenen ücret, sermaye için T.C. Ziraat Bankasının 2018 yılında bitkisel üretime uygulamış olduğu faiz oranı dikkate alınmıştır (Yılmaz ve Yurdakul, 2000). Çalışmada çeltik üretimine yönelik; Marjinal Gelir (MG), Marjinal Maliyet (MM) ve Marjinal Etkinlik Katsayıları da (MEK) Marjinal Teknik ikame (MTi) oranları hesaplanarak yorumlanmıştır. 


\section{Ekonometrik analizlerde uygulanan yöntem}

Araştırmada çeltik üretiminden elde edilen miktar ile üretimde kullanılan girdiler arasındaki ilişkilerin tespit edilmesinde Cobb-Douglas tipi fonksiyondan yararlanılmıştır. Literatür taramalarında bu tip fonksiyonun tarımsal üretim faaliyetlerine yönelik olarak yapılan fonksiyonel analizlere uygun olduğu belirtilmektedir (Özçelik, 1989). Cobb-Douglas tipi fonksiyona ilişkin ana kitleye ait denklem;

\section{$Y=a X 1^{b 1} X 2^{b 2} X 3^{b 3} X n^{b n}$}

şeklinde oluşmaktadır. Denklem, her iki tarafın logaritması alındığında;

$\log Y=\log \alpha+\beta 1 \log x 1+\beta 2 \log x 2+\ldots x+\beta k \log x k+$ şekline dönüşmektedir. Denklemde yer alan $\beta_{i}$ sembolleri üretim faktörlerine ait üretim elastikiyetlerini belirtmektedir $\left(\beta_{i}=1,2, . . n\right)$. Üretim elastikiyetlerine ilişkin katsayılarının $\left(\beta_{i}\right)$ önem düzeyleri, $\boldsymbol{t} \boldsymbol{\beta} i=\boldsymbol{\beta} \boldsymbol{i} / \operatorname{se}(\boldsymbol{\beta} i)$

formülü yardımıyla test edilmektedir. Belirlenen $\mathrm{t} \beta_{i}$ değeri, "t-tablosu"nda (n-k-1) serbestlik derecesini gösteren satır ile istenen önem seviyesine ilişkin sütunun birleştiği noktadaki değeri ile karşılaştırılmaktadır.

Çeltik üretiminin regresyon denklemine ait; çoklu regresyon (R) ve belirleme katsayısı $\left(R^{2}\right)$, bağımsız değişkenlere ilişkin elastikiyet katsayıları $(\beta i)$, standart hataları(se $\beta i)$ ve önem düzeyleri $(\mathrm{t} \beta i)$, değişkenlerin geometrik ortalamaları $\left(X_{i} G, Y G\right)$, basit korelasyon katsayıları $\left(\mathrm{ri}_{j}\right)$ ile denklemin standart sapması (S) ve önem seviyesi (F değeri) uygun bir istatistik paket programı yardımıyla yapılan regresyon analizi sonucunda belirlenmiştir. Çalışmada tahmin denklemiyle ilgili olarak; Belirleme Katsayısı $\left(R^{2}\right)$, Kısmi Korelasyon Katsayılarının $\left(b_{i}\right)$ Önem Testi, İçsel Bağıntı (otokorelasyon) ve Çoklu Bağıntı Varlığı (multicollinearity) testleri de yapılmıştır.

Incelenen işletmelerde çeltik üretiminde kullanılan üretim faktörlerinin Marjinal Gelirinin (MG) belirlenmesinde aşağıda belirtilen formül kullanılmıştır (Karagölge, 1973).

$$
M j G x j=\beta j \frac{Y G \text { (ort) }}{X j G \text { (ort) }} F y
$$

Faktörlere ilişkin Marjinal Etkinlik Katsayısının (MEK) belirlenmesinde yararlanılan formül aşağıda verilmiştir (Akçay ve Uzunöz, 1999).

$$
\begin{aligned}
& \text { MEK }=\frac{\text { Faktörlerin Marjinal Geliri }}{\text { Faktörlerin Marjinal Maliyeti (Faktör Fiyat } l)} \\
& \text { Üretim fonksiyonundan geometrik }
\end{aligned}
$$

ortalamalar kullanılarak üretimde kullanılan değişkenlerin $\left(X_{i}\right)$ marjinal verimi;

$$
\text { MVXi }=\beta \mathbf{i} * Y G / X i G
$$

formülü yardımıyla tespit edilmiştir (Zoral, 1973). Üretimde kullanılan faktörler arasındaki teknik ikame haddi (marjinal teknik ikame oranı), diğer bir ifadeyle $Y$ seviyesinde bir üretim miktarını elde etmek için $X_{1}$ faktörü miktarına karşılık, $X_{2}$ faktörünün ne miktarda kullanılması gerektiği;

$$
\text { MTIO } x 2 / x 1=\frac{X 1 G \text { Marjinal Verim }}{X 2 \text { GMarjinal Verim }}
$$

veya;

\section{MTIO $x 2 / x 1=b 1 . \times 2 G / b 2 . X 1 G$}

formülleri kullanılarak hesaplanmıştır.

Araştırma kapsamında Çanakkale ilinde 74 tarım işletmesinden elde edilen veriler yardımıyla çeltik üretim miktarı ile; tohum, gübre, tarımsal mücadele ilacı, sulama işgücü, sulama için elektrik kullanım miktarı ve üretimin tamamı için kullanılan mazot miktarı arasındaki ilişkiler Cobb-Douglas üretim fonksiyonu kullanılarak analiz edilmiştir (Neill, 2002). Çalışmada çeltik üretim fonksiyonunda yer alan değişkenler aşağıda gösterilmiştir.

$Y=$ Çeltik üretim miktarı $\left(\mathrm{kg} \mathrm{da}^{-1}\right)$ : Birim alandan elde edilen çeltik üretim miktarına ait değerler kullanılmıştır.

Fonksiyonda yer alan bağımsız değişkenler ise aşağıda verilmiştir.

$\mathrm{X}_{1}=$ Tohum miktarı $\left(\mathrm{kg} \mathrm{da}^{-1}\right)$

$\mathrm{X}_{2}=$ Çeltik sulamasında kullanılan elektrik (KW da$\left.{ }^{1}\right)$,

$X_{3}=$ Saf gübre kullanım miktarı $\left(\mathrm{kg} \mathrm{da}^{-1}\right)$,

$\mathrm{X}_{4}=$ Zirai mücadele ilacı kullanım miktarı (lt da ${ }^{-1}$ )

$X_{5}=$ Üretimin tüm aşamalarında kullanılan toplam mazot miktarı (lt da-1),

$\mathrm{X}_{6}=$ Sulamada kullanılan işgücü $\left(\right.$ saat $\left.\mathrm{da}^{-1}\right)$,

\section{Bulgular ve Tartışma}

Yapılan araştırmada Çanakkale ilinde örnekleme yöntemine göre tespit edilen 74 çeltik üretim işletmesinden elde edilen veriler kullanılarak yapılan ekonometrik analiz sonucunda üretimde yer alan değişkenler arasındaki fonksiyonel bağıntı;

$Y=8.721 * \quad X_{1}^{0.284 *} X_{2}^{0.053} * X_{3}^{0.243} * X_{4}^{0.119}$ $* \mathrm{X}_{5} 0.398 * \mathrm{X}_{6}{ }^{-0.095}$

( $\left.S=0.172 ; R=0.986 ; R^{2}=0.969 ; F=386.39\right)$

şeklinde belirlenmiştir.

Denkleme ilişkin çoklu korelasyon ve determinasyon katsayıları ( $F_{\text {hesap }}>F_{\text {tablo }}$ ) \%1 olasılık seviyesinde anlamlı bulunmuştur (Çizelge 1). Elde edilen fonksiyona ilişkin hesaplanan determinasyon katsayısı; çeltik üretim miktarındaki değişimlerin yaklaşık \%97'sinin modelde yer alan bağımsız değişkenler tarafından ifade edilebileceğini ve seçilen modelin uygun olduğunu göstermektedir. Araştırmada oluşturulan denklemde otokorelasyon varlığı "Durbin Watson (DW) Testi” uygulanarak test edilmiş olup, denkleme ait $\mathrm{DW}_{\text {hesap }} 1.871$ olarak hesaplanması nedeniyel pozitif otokorelasyon testi uygulanmıştır. Yapılan test sonucunda fonksiyona yönelik pozitif korelasyon 
durumunun bulunmadığı $\left(\mathrm{DW}_{\mathrm{h}}\right.$ 1.871> $\mathrm{DW}_{\mathrm{U}(0.05)}$

1.834) anlaşılmıştır (Çizelge 1 ve 2).

Çizelge 1. Tahmin denklemine ait temel istatistikler

Durbin-

Watson

\begin{tabular}{|c|c|c|c|c|c|c|c|c|c|c|}
\hline Model & $\mathrm{R}$ & R Square & $\begin{array}{c}\text { Adjusted R } \\
\text { Square }\end{array}$ & $\begin{array}{l}\text { Std. Error of } \\
\text { the Estimate }\end{array}$ & $\begin{array}{c}\text { R Square } \\
\text { Change }\end{array}$ & F Change & df1 & $\mathrm{df} 2$ & $\begin{array}{c}\text { Sig. F } \\
\text { Change }\end{array}$ & \\
\hline 1 & .986 & .972 & .969 & .07804 & .972 & 386.39 & 6 & 67 & .000 & 1.871 \\
\hline
\end{tabular}

Çizelge 2. Çeltik üretim fonksiyonu varyans analiz tablosu

\begin{tabular}{lccccc} 
& $\begin{array}{c}\text { Serbestlik } \\
\text { Derecesi }\end{array}$ & Kareler Toplamı & Kareler Ortalaması & F değeri & P değeri \\
\hline Regresyon & 6 & 14.120 & 2.353 & 386.392 & 0.000 \\
Kalan & 67 & 0.408 & .006 & & \\
Toplam & 73 & 14.528 & & & \\
\hline
\end{tabular}

Bağımsız değişkenlere ait üretim elastikiyeti katsayılarının pozitif karakterli olduğu elastikiyetleri incelendiğinde; sulamada kullanılan işgücü faktörü hariç diğer faktörlerin üretim görülmektedir (Çizelge 3 ).

Çizelge 3. Üretim faktörlerine ait üretim elastikiyetleri

\begin{tabular}{|c|c|c|c|c|c|c|c|}
\hline & $\begin{array}{c}\mathrm{X} 1 \\
\text { (tohum) }\end{array}$ & $\begin{array}{c}\mathrm{X} 2 \\
\text { (elektrik) }\end{array}$ & $\begin{array}{c}\text { X3 } \\
\text { (gübre) }\end{array}$ & $\begin{array}{c}\text { X4 } \\
\text { (ilaç) }\end{array}$ & $\begin{array}{c}\text { X5 } \\
\text { (mazot) }\end{array}$ & $\begin{array}{c}\text { X6 } \\
\text { (işgücü) }\end{array}$ & $(\Sigma \beta i)$ \\
\hline Üretim elastikiyetleri $(\beta \mathrm{i})$ & 0.284 & 0.053 & 0.243 & 0.119 & 0.398 & -0.095 & 1.002 \\
\hline Standart hata (se $\beta i)$ & 0.141 & 0.083 & 0.112 & 0.049 & 0.121 & 0.101 & - \\
\hline$t \beta i$ & $2.091 *$ & 0.714 & $2.160 *$ & $2.331^{*}$ & $3.487^{*}$ & -1.342 & - \\
\hline
\end{tabular}

$\left(^{*}\right)$ : \%5 ihtimal düzeyinde önemli.

Elde edilen denklemde kullanılan girdilerin üretim elastikiyeti katsayıları (sulamada kullanılan işgücü girdisi hariç) pozitif işaretlidir. Fonksiyonda yer alan faktörlerin üretim elastikiyetleri toplamı $\left(\Sigma \beta_{i}\right)$ 1.002'dir. Bu durum çeltik üretiminde ölçeğe göre artan getiriyi ifade etmektedir. Kısacası, çeltik üretiminde tohum, gübre, ilaç, elektrik ve mazot girdi miktarları \%1 artırıldığında, üretim miktarı \%1'in biraz üzerinde de olsa artış göstermektedir.

Tohum $\left(X_{1}\right)$, gübre $\left(X_{3}\right)$, ilaç $\left(X_{4}\right)$ ve mazot $\left(X_{5}\right)$ girdilerinin üretim elastikiyeti katsayıları \%5 intimal düzeyinde önemli bulunmuştur. Teorik açıdan konuya yaklaşıldığında çeltik üretiminde kullanılan tohum girdisindeki \%1'lik artışın üretimi $\% 0.284$; elektrik girdisindeki \%1'lik artışın çeltik üretimini \%0.053; gübre girdisindeki \%1'lik artışın üretimi \%0.243; ilaç girdisindeki \%1'lik artışın üretimi $\% 0.119$ ve mazot girdisindeki artışın üretimi \%0.398 oranında artıracağı söylenebilir. Pratik açıdan ise çeltik üretiminde nitelikli girdi kullanımının üretim düzeyinde belirli bir aşamaya kadar artış sağlayabileceği şeklinde yorumlanması daha uygundur.

Fonksiyonda yer alan üretim faktörlerinin elastikiyet katsayıları toplamı $\left(\Sigma \beta_{\mathrm{i}}\right) \quad 1.002$ olarak hesaplanmıştır. Bu değer ölçeğe sabit getiriye yakın olmakla birlikte ölçeğe artan getiriyi göstermektedir. Araştırmada çeltik üretim miktarında etkili olan üretim faktörlerine ait marjinal ürün değerleri ve marjinal etkinlik katsayıları Çizelge 4'te verilmiştir.

Çizelge 4. Model katsayılarının marjinal kıymetleri ve etkinlik katsayıları

\begin{tabular}{lrrrrrr} 
& \multicolumn{1}{c}{ X1 } & \multicolumn{1}{c}{ X2 } & \multicolumn{1}{c}{ X3 } & \multicolumn{1}{c}{ X4 } & \multicolumn{1}{c}{ X5 } & Y \\
& (tohum) & (elektrik) & \multicolumn{1}{c}{ (gübre) } & \multicolumn{1}{c}{ (ilaç) } & \multicolumn{1}{c}{ (mazot) } & (mo,060.17 \\
\hline Geometrik ortalama & $1,900.76$ & $21,062.04$ & $3,125.85$ & 82.22 & $2,359.57$ & - \\
Marjinal ürün kıymeti (TL) & 29.69 & 0.50 & 15.44 & 287.64 & 33.52 & - \\
Faktör fiyatları (TL) & 1.13 & 1.13 & 1.13 & 1.13 & 1.13 & - \\
Marjinal etkinlik katsayısı & 26.28 & 0.44 & 13.67 & 254.55 & 29.67 & - \\
\hline
\end{tabular}

Çizelge 4'ün incelenmesinde de anlaşılacağı üzere çeltik üretiminde kullanılan girdiler içinde en yüksek marjinal etkinlik katsayısı tarımsal mücadele ilacına (X4) aittir. Bu değişkeni sırası ile mazot (X5) 
ve tohum girdisi (X1) izlemektedir. Marjinal ürün değerlerinin belirlenmesinde faktör fiyatları olarak normal faiz oranından 1 TL fazlası dikkate alınmıştır (Rehber ve Erkuş, 1984; Çelik ve Bayramoğlu, 2007; Vural ve Turhan, 2011). Marjinal etkinlik katsayılarına göre, ilaç, mazot, tohum ve gübre girdileri üretim faktörleri ekonomik optimum düzeyinin altında $(x j>1)$, elektrik girdisi ise ekonomik optimumun üzerinde $(x j<1)$, kullanılmaktadır. $\mathrm{Bu}$ nedenle marjinal etkinlik katsayısı yüksek olan ilaç, mazot, tohum ve gübre girdilerinin kullanımının artırıması, elektrik kullanımının ise azaltılması önerilebilir. Diğer bir ifade ile; mazot kullanımı özellikle toprak hazırlığında yoğun olarak kullanılması nedeniyle toprak hazırlığına gereken ihtimam gösterilmeli, üretimde daha nitelikli (sertifikalı) tohum kullanımına ağırlık verilmeli, toprak analizi yapıldıktan sonra tavsiye edilen miktarlara göre kullanımı teşvik edilmeli, üretimde yaklaşık dekar başına 1 It civarında tüketilen tarımsal mücadele ilaçlarının ise çevreye daha duyarlı ilaçlar arasından seçilmesine daha fazla özen gösterilmesi gerekmektedir.

Üretim faktörleri arasındaki marjinal teknik ikame hadleri dikkate alındığında, $X_{1}$ (tohum) faktörünün $X_{2}$ (elektrik) ve $X 3$ (gübre) faktörlerine oranla az, $X_{4}$ (ilaç) faktörüne göre aşırı ve $X_{5}$ (mazot) faktörüne oranla ise ekonomik optimuma yakın düzeyde kullanıldığı anlaşılmaktadır. X2 (elektrik) faktörü ise $X_{3}$ (gübre), $X_{4}$ (ilaç) ve $X_{5}$ (mazot) faktörlerine oranla aşırı düzeyde kullanılmaktadır. $X_{3}$ (gübre) faktörü, $X_{4}$ (ilaç) ve $X_{5}$ (mazot) girdilerine kıyasla fazla kullanılmaktadır. $X_{4}$ (ilaç) girdisi ise $X_{5}$ (mazot) girdisine oranla $a z$ kullanılmaktadır (Çizelge 5).

Çizelge 5. Faktörler arası marjinal teknik ikame ve fiyat oranları

\begin{tabular}{|c|c|c|c|c|c|}
\hline $\begin{array}{l}\text { Üretim } \\
\text { Faktörleri }\end{array}$ & $\begin{array}{c}\text { Marjinal Teknik İkame ve Fiyat } \\
\text { Oranları }\end{array}$ & $\begin{array}{c}\mathrm{X}_{2} \\
\text { (elektrik) }\end{array}$ & $\begin{array}{c}\mathrm{X}_{3} \\
\text { (gübre) }\end{array}$ & $\begin{array}{c}\mathrm{X}_{4} \\
\text { (zirai } \\
\text { mücadele } \\
\text { ilacı) }\end{array}$ & $\begin{array}{c}\mathrm{X}_{5} \\
\text { (mazot) }\end{array}$ \\
\hline $\mathrm{X}_{1}$ (tohum) & $(\mathrm{dX} 1 / \mathrm{dX} 2) /(\mathrm{FX} 2 / \mathrm{FX} 1)$ & 0.0168 & 0.5203 & 9.6868 & 1.1289 \\
\hline $\mathrm{X}_{2}$ (elektrik) & $(\mathrm{dX} 2 / \mathrm{dX} 3) /(\mathrm{FX} 3 / \mathrm{FX} 2)$ & & 30.89 & 57.5167 & 67.0309 \\
\hline $\mathrm{X}_{3}$ (gübre) & $(\mathrm{dX} 3 / \mathrm{dX} 4) /(\mathrm{FX} 4 / \mathrm{FX} 3)$ & & & 18.6179 & 2.1698 \\
\hline $\begin{array}{l}\mathrm{X}_{4}(\text { zirai } \\
\text { mücadele } \\
\text { ilacı) }\end{array}$ & $(d X 4 / d X 5) /(F X 5 / F X 4)$ & & & & 0.1165 \\
\hline
\end{tabular}

Çeltik üretiminde, marjinal teknik ikame oranları incelendiğinde, ekonomik optimum düzeyde bir girdi kullanımı bileşiminin olamadığı görülmektedir. Belirlenen modelde yapılan testler sonucunda otokorelasyon ve çoklu bağlantı probleminin olmadığı anlaşılmıştır.

Çeltik üretimi konusunda yapılan bazı çalışmalarda gerek Türkiye'de gerekse Uzak Doğu Asya ülkelerinde Cobb-Douglas üretim fonksiyonu yardımıyla üretim miktarı ile girdiler arasında ilişkiler incelenmiştir. Bu bölümde konu ile ilgili olarak yapılan çalışlarda elde edilen bulgular genel hatlarıyla verilmiş ve araştırma bulgularının karşılaştırılması yapılmıştır. Edirne ilinde 97 üreticinin yer aldığı bir araştırmada tohum, gübre, tarımsal mücadele ilacı, parsel sayısı, eğitim durumu ve traktör gücü faktörlerinin üretim miktarı üzerine etkisi Cobb-Douglas üretim fonksiyonu kullanılarak analiz edilmiştir. Çalışmada elde edilen fonksiyonun çoklu belirleme katsayısı $\left(R^{2}\right)$ 0.91, bağımsız değişkenleri elastikiyet katsayıları toplamı 1.15 olarak hesaplanmıştır. Fonksiyonda yer alan tohum, gübre, tarımsal mücadele ilacı, parsel sayısı değişkenleri \%1 düzeyinde önemli bulunmuştur. Çalışmada içsel bağıntı probleminin olmadığı tespit edilmiştir (DW
Testi ${ }_{h}$ 2.08, Von Neumann Testi ${ }_{h}$ 2.010). Elde edilen fonksiyonda yer alan tohum girdisinin fazla, gübrenin az tarımsal mücadele ilacının ise aşırı kullanıldığı sonucuna varılmıştır. Faktör Bileşimlerinin Marjinal Etkinlik Katsayıları incelendiğinde ise tohum faktörünün gübreye oranla fazla, tarımsal mücadele ilacına göre ise az kullanıldığı belirtilmiştir. Gübre faktörünün ise tarımsal mücadele ilacı faktörüne oranla az kullanıldığı sonucuna varılmıştır (Güngör ve Semerci, 2000).

Hindistan'ın Kerala eyaletinde 71 üreticinin katılımı ile yapılan bir çalışmada Cobb-Douglas üretim fonksiyonu kullanılarak 8 farklı değişkenin çeltik üretiminin geliri üzere etkisi belirlenmeye çalışılmıştır. Elde edilen fonksiyonun $\mathrm{R}^{2}$ değeri 0.86 olarak belirlenmiştir. Çalışmada fonksiyonda yer alan değişkenlerden üretim alanı (EK:0.65), işgücü kullanımı (EK:0,55) ve gübre kullanımı (EK:0.17) değişkenleri \%1 düzeyinde önemli bulunmuştur. Belirtilen her 3 değişkenin de marjinal etkinlik katsayısı 1'in üzerinde olduğu belirlenmiştir. Tohum, çiftlik gübresi ve traktör değişkenlerinin ise etkinlik katsayıları negatif olarak tespit edilmiştir. Denklemde yer alan değişkenlerin elastikiyet 
katsayıları toplamı 1.39 olarak hesaplanmıştır (Suresh ve Keshava Reddy, 2006).

Gana'da 70 çeltik üreticisinin yer aldığı çalışmada ise 5 farklı değişkenin çeltik üretim miktarı üzere etkisi saptanmaya çalışılmıştır. CobbDouglas üretim fonksiyonu kullanılarak yapılan çalışmada elde edilen fonksiyonun $\mathrm{R}^{2}$ değeri 0.62 , DW Testih 2.11 olarak belirlenmiştir. Çalışmada fonksiyonda yer alan değişkenlerden üretim alanı (EK:0.44) ve gübre kullanımı (EK:-0.29) değişkenleri \%1 düzeyinde önemli bulunmuştur. Arazi miktarı, gübre ve tohum değişkenlerine ait marjinal etkinlik katsayısı 1'in üzerinde olduğu belirlenmiştir. Sadece kimyasal mücadele ilacı kullanımı değeri negatif karakterli bulunmuştur. Denklemde yer alan değişkenlerin elastikiyet katsayıları toplamı 0.58 olarak hesaplanmıştır (Nimoh ve ark., 2012).

Hindistan'da 2012-13 döneminde 288 çeltik üreticisinin yer aldığı çalışmada 7 farklı değişkenin çeltik üretim miktarı üzere etkisi tespit edilmeye çalışılmıştır. Cobb Douglas üretim fonksiyonundan yararlanılarak yürütülen araştırmada elde edilen fonksiyonun $\mathrm{R}^{2}$ değeri 0.75 , olarak belirlenmiştir. Çalışmada fonksiyonda yer alan değişkenlerden işgücü, hayvan çekigücü, hayvan gübresi ve potaslı gübre değişkenleri \%5 düzeyinde önemli bulunmuştur. Denklemde yer alan değişkenlerin elastikiyet katsayıları toplamı 1.88 olarak hesaplanmıştır (Hile ve ark., 2016).

Hindistan'da 2011-12 döneminde iki eyalette toplam 100 çeltik üreticisinin yer aldığı çalışmada 6 farklı değişkenin çeltik üretim miktarı üzere etkisi belirlenmeye çalışılmıştır. Çalışmada elde edilen veriler 2 eyalet için ayrı ayrı verilmiştir. Himachal Pradesh Eyaleti'nde Cobb-Douglas üretim fonksiyonundan yararlanılarak yürütülen araştırmada elde edilen fonksiyonun $\mathrm{R}^{2}$ değeri 0.60 olarak belirlenmiştir. Çalışmada fonksiyonda yer alan değişkenlerden hayvan gübresi ve kimyasal gübre değişkenleri \%5 düzeyinde önemli bulunmuştur. Denklemde yer alan değişkenlerin elastikiyet katsayıları toplamı 0.53 olarak hesaplanmıştır. Ülkenin Manipur Eyaleti'nde yürütülen araştırmada elde edilen fonksiyonun $R^{2}$ değeri 0.73 olarak belirlenmiştir. Çalışmada fonksiyonda yer alan değişkenlerden tohum girdisi değişkenleri \%1 düzeyinde önemli bulunmuştur. Denklemde yer alan değişkenlerin elastikiyet katsayıları toplamı 1.60 olarak hesaplanmıştır (Yumnam ve ark., 2017).

Endonezya'da 100 çeltik üreticisinin yer aldığı çalışmada 5 farklı değişkenin çeltik üretim miktarı üzere etkisi incelenmiştir. Cobb-Douglas üretim fonksiyonu kullanılarak yapılan çalışmada elde edilen fonksiyonun $\mathrm{R}^{2}$ değeri 0.98, DW Testi 1.78 olarak belirlenmiştir. Çalışmada fonksiyonda yer alan değişkenlerden üretim alanı, işgücü, tohum ve zirai mücadele ilacı değişkenleri \%1 düzeyinde önemli bulunmuştur. Denklemde yer alan değişkenlerin elastikiyet katsayıları toplamı 0.96 olarak hesaplanmıştır (Pudaka ve ark., 2018).

Malezya'da 396 çeltik üreticisinin yer aldığı çalışmada ise 5 farklı değişkenin çeltik üretim miktarı üzerine etkisi araştırılmıştır. Cobb-Douglas üretim fonksiyonu kullanılarak yapılan çalışmada elde edilen fonksiyonun $R^{2}$ değeri 0.90 belirlenmiştir. Çalışmada fonksiyonda yer alan değişkenlerden tohum, kimyasal gübre, işgücü, pestisit girdileri \%1, herbisit girdisi ise \%5 düzeyinde önemli bulunmuştur. Çalışmada pestisit ve herbisit değişkenlerinin ait marjinal etkinlik katsayısı 1'in üzerinde olduğu belirlenmiştir. Denklemde yer alan değişkenlerin elastikiyet katsayıları toplamı 1.07 olarak hesaplanmıştır (Adedoyin ve ark., 2016).

Endonezya'da 159 çeltik üreticisinin yer aldığı çalışmada ise 5 farklı değişkenin çeltik üretim miktarı üzere etkisi tespit edilmeye çalışımıştır. Cobb-Douglas üretim fonksiyonu kullanılarak yapılan çalışmada elde edilen fonksiyonun $R^{2}$ değeri 0.87 belirlenmiştir. Çalışmada fonksiyonda yer alan değişkenlerden üretim alanı, işgücü, pestisit girdileri \%1 düzeyinde önemli bulunmuştur. Çalışmada pestisit, kimyasal gübre ve işgücüne ait marjinal etkinlik katsayısı 1'in üzerinde olduğu belirlenmiştir. Denklemde yer alan değişkenlerin elastikiyet katsayıları toplamı 1.28 olarak hesaplanmıştır (Ida ve Azhar, 2018).

Yapılan çalışmada elde edilen fonksiyona ait çoklu belirleme katsayısının (0.97) diğer çalışmalarda hesaplanan değerlere göre (0.60-0.98) daha yüksek olduğunu ortaya koymaktadır. Bu çalışmaya parallel olarak, yapılan bazı çalışmalarda Durbin Watson (DW) Testinin değişkenler arasında pozitif ya da negatif yönlü bir ilişkinin olmadığı görülmüştür (Güngör ve Semerci, 2000; Nimoh ve ark., 2012; Pudaka ve ark., 2018). Çeltik üretiminde kullanılan girdiler ve üretim miktarı üzerindeki etkileri ülkeden ülkeye değişiklik gösterebilmektedir. Zira konu ile ilgili yapılan çalışmalar incelendiğinde, her ülkede sahip olunan kaynakların üretim miktarı üzerindeki etkisinin farklılık gösterdiği anlaşılmaktadır.

$\mathrm{Bu}$ çalışmada fonksiyonda yer alan faktörlerin üretim elastikiyeti katsayıları toplamı $\left(\Sigma \beta_{i}\right) \quad 1.002$ olup, ölçeğe artan getiriyi ifade etmektedir. Ida ve Azhar (2018), Adedoyin ve ark. (2016), Yumnam ve ark. (2017), Hile ve ark. (2016), Suresh ve Keshava Reddy (2006), Güngör ve Semerci (2000) yapmış oldukları araştırmalarda elde etmiş oldukları fonksiyona ait denklemin üretim elastikiyetleri toplamını $1^{\prime}$ in üzerinde bulmuşlardır. Ancak aynı değer Nimoh ve ark. 
(2012) Pudaka ve ark. (2018) tarafından yapılan araştırmada 1 'in altında bulunmuştur.

Denklemlerde yer alan üretim faktörlerinin önem düzeyleri, etkinlik katsayılarına ait değerin 1'in altında ve üzerinde olma durumu her araştırmada farklılık göstermektedir. Bunun temel nedeni ise her ülkede çeltik üretiminde kullanılan teknolojinin ve üretim miktarı üzerinde faktörlerin ağırık düzeylerinin farklılık göstermesinden kaynaklanmaktadır. Örneğin yapılan araştırmada hayvan çeki gücü hayvan çeki gücü ve hayvansal gübre kullanımına rastlanılmazken çeltik üretiminin yoğun olduğu Hindistan'da bu girdilerin yoğun olarak kullanıldığı üretim miktarı üzerinde de etkili oldukları anlaşılmıştır (Hile ve ark., 2016).

\section{Sonuç ve Öneriler}

2019 yılı Tüik verilerine göre Çanakkale ili, Türkiye çeltik ekim alanları ve üretim miktarı bakımından Edirne, Samsun ve Balıkesir illerinden sonra 4.sırada gelmektedir. Ülke çeltik üretiminde önemli bir konuma sahip olması nedeniyle Çanakkale ili araştırma alanı olarak belirlenmiştir. Araştırmanın verileri Tabakalı Örnekleme Yöntemi ile belirlenen 74 tarım işletmesinden elde edilmiştir. Yapılan araştırmada çeltik üretim miktarı ile; tohum, gübre, tarımsal mücadele ilacı, sulama işgücü, sulama için elektrik kullanım miktarı ve mazot miktarı (üretimin tamamı için kullanılan) arasındaki ilişkiler Cobb-Douglas tipi fonksiyon kullanılarak incelenmiştir.

Çalışmada çeltik üretimine ilişkin oluşturulan fonksiyonda; tohum masrafı $\left(X_{1}\right)$ gübre masrafı $\left(X_{3}\right)$, tarımsal mücadele ilacı masrafı $\left(X_{4}\right)$ ve mazot $\left(X_{5}\right)$ girdilerinin üretim elastikiyetleri \%5 ihtimal düzeyinde önemli bulunmuş, üretim miktarı üzerinde etkili olan faktörlerin üretim elastikiyetleri katsayıları toplamının ise $\left(\Sigma \beta_{i}: 1.002\right)$ ölçeğe artan getiriyi ifade ettiği sonucuna varılmıştır.

Tahmin denkleminde yer alan değişkenler arasında en yüksek marjinal etkinlik katsayısı 254.55 ile tarımsal mücadele ilacı değişkeni $\left(X_{4}\right)$ olmuştur. Marjinal teknik ikame oranlarına göre ise tohum $\left(X_{1}\right)$ faktörünün mazot faktörüne $\left(X_{5}\right)$ oranla ekonomik optimuma en yakın düzeyde kullanılan girdi bileşenleri olduğu sonucuna varılmıştır.

Araştırma alanında elde edilen bulgular tarımsal destekler içinde çeltik üretimine verilen desteklerin artırılması halinde üretim alanlarında ve üretim miktarında artış olacağını göstermektedir. Bu bakımdan çeltik üretimine yönelik olarak verilen desteklerin günümüz şartlarına uygun ve reel olarak belirlenmesi gerekmektedir.

Teşekkür: Yürütülen proje FBA-2018-2605 nolu ile Çanakkale Onsekiz Mart Üniversitesi Bilimsel
Araştırma Projeleri Koordinasyon Birimi'nce desteklenmiştir. Projenin yürütülmesi aşamasında sağlamış oldukları teknik desteklerden dolayı başta Tarım ve Orman Bakanlığı Çanakkale ì Müdürlüğü olmak üzere Biga, Ezine ve Gelibolu illçe Müdürlüğü yöneticileri ve teknik personeline, anket aşamasında yöneltilen sorulara vermiş oldukları içten ve samimi yanıtlar nedeniyle Çanakkale ili çeltik üreticilerine teşekkür ederiz.

Çıkar Çatışması Beyanı: Makale yazarları aralarında herhangi bir çıkar çatışması olmadığını beyan ederler.

Araştırmacıların Katkı Oranı Beyan Özeti: Yazarlar makaleye eşit oranda katkı sağlamış olduklarını beyan ederler.

\section{Kaynaklar}

Adedoyin, A.O., Shamsudin, M.N., Radam, A., Latif, i.A. 2016. Resource-Use and Allocative Efficiency of Paddy Rice Production in Mada, Malaysia. Journal of Economics and Sustainable Development, 7 (1): 49-55.

Akçay, Y., Uzunöz, M. 1999. Tarım işletmelerinde kaynak kullanımı etkinliği üzerine bir araştırma: Niksar Ovası örneği. Tarım ve Mühendislik Dergisi. 59: 29-38.

Çelik, Y., Bayramoğlu, Z. 2007. Şanlıurfa ili Harran Ovasında pamuk üretiminin fonksiyonel analizi. Selçuk Üniversitesi Ziraat Fakültesi Dergisi 21 (41):42-50.

Çelik, A.D., Semerci, A., Gül, A. 2018. Türkiye'de çeltik üretimi, ticareti ve destekleme politikaları. $3^{\text {rd }}$ International Mediterranean Science and Engineering Congress (IMSEC 2018) Çukurova University, Congress Center, October 24-26, 2018, Adana / TURKEY, pp.31-34.

FAO. 2019. Bitkisel üretim istatistikleri. (erişim: http://www.fao.org/faostat/en/\#data/QC, 29.04.2019)

Güngör, H., Semerci, A. 2000. Edirne Iili Çeltik Üretiminde Verimlilik Analizleri. MPM Verimlilik Dergisi, Sayı: 2000/2, s.191-204, Ankara.

Hile, R.B., Darekar, A.S. , Dattarkar, S.B. 2015. Economic analysis and impact assessment of production technology of paddy of Konkan Region in Maharashtra. International Journal of Commerce And Business Management, 8 (2): 143-152

Hile, R. B., Sanap, D. J. , Yadav, D. B. 2016. Impact assessment of production technology of paddy in Maharashtra. Journal of Crop and Weed, 12(3):36-40. 
IGC,2020. International Grains Council. (erişim: https://www.igc.int/en/markets/marketinfo -sd.aspx, 27.04.2021)

Ida, F.C., Azhar, M. 2018. Efficiency analysis of production factors of wetland paddy farming in West Aceh Regency. Russian Journal of Agricultural and Socio-Economic Sciences, 9 (81): 424 - 428.

Kaka, Y., Shamsudin, M.N., Radam, A., Latif, İ.A. 2016. Profit efficiency among paddy farmers: A Cobb-Douglas stochastic frontier production function analysis. Journal of Asian Scientific Research, 6(4): 66-75

Karagolge, C. 1973. Arazi tasarruf şekillerine göre erzurum ilindeki tarım işletmelerinin ekonometrik analizi. Ankara Ün. Yay. No:312. Zir. Fak. Yay. No:153, Arş. Seri No:90, Sevinç Matb., Ankara, s.8-24

Kudal, G.Ç. 2019. Edirne ilinde çeltik üretim ve destekleme politikalarının incelenmesi. Çanakkale Onsekiz Mart Ün. Fen Bil. Ens. Tar. Ekon. ABD. Yüksek Lisans Tezi. Çanakkale. $45 \mathrm{~s}$.

Neill, R.J. 2002. "Production and production functions: some Implications of a refinement to process analysis", Journal of Economic Behaviour \& Organization. 51(4): 507-521.

Nimoh, F., Tham-Agyekum, E.K., Nyarko, P.K. 2012. Resource Use Efficiency in Rice Production: the Case of Kpong Irrigation Project in the Dangme West District of Ghana. International Journal of Agriculture and Forestry, 2(1): 35-40.

Özçelik, A. 1989. Ankara şeker fabrikası civarındaki şekerpancarı yetiştiren tarım işletmelerinde şekerpancarı ile buğday için fiziki üretim girdileri ve üretimin fonksiyonel analizi. A.Ü. Zir. Fak. Yay. No:1113, Ankara, 1989.

Öztürk, D. Akçay, Y. 2010. Güney Marmara Bölgesi'nde çeltik üretiminin genel bir değerlendirmesi. GOÜ Zir. Fak. Derg, 27(2): 61-70

Pudaka, D.L., Rusdarti, P., Prasetyo, E. 2018. Efficency Analysis of Rice Production and Farmers' Income in Sengah Temila District Landak Regency. Journal of Economic Education. 7 (1): 31 - 38.

Rehber E. Erkuş A. (1984). Nevşehir'de Patates Üreten Tarım İşletmelerinin Ekonomik Analizi, Ankara Üniversitesi, No. TE.1, Ankara.

Semerci, A. 1998. Trakya'da tarımsal yapı ve başlıca ürünlerde verimlilik analizleri. Trakya Üniversitesi Fen Bil. Enst. Tarım Ekonomisi Anabilim Dalı. (Basılmamış Doktora Tezi), Edirne, $249 \mathrm{~s}$
Semerci, A., Everest, B., Tan, S. 2019. Türkiye'de çeltik ekim alanları, üretim miktarı ve verim değerlerinde meydana gelen değişimlerin incelenmesi. International Balkan and Near Eastern Social Sciences Congress Series XI. IBANESS Congress Series, March 09-10, 2019 Tekirdağ, Turkey, pp.107-113.

Semerci, A. 2020. Input usage and cost analysis in paddy production: A case study of Çanakkale City-Turkey. Custos e @gronegócio on line, 16 (2:) 277-306.

Siagian, V., Siregar, H., Fariyanti, A., Nainggolan, K. 2019. Analysis of factors that influence the production of wetland rice in Banten Province. IOP Conf. Series: Earth and Environmental Science 399.(erişim: https://doi.org/10.1088/17551315/399/1/012073) Bogor, Endonezya.

Sikdar, M.M.H., Alam, M.A., Hossain, M.I.2008. Factors affecting the technical efficiency of Boro rice production in Bangladesh a CobbDouglas stochastic frontier analysis. J. Bangladesh Agril. Univ, 6(1): 215-226

Suresh, A., Keshava Reddy, T.R. 2006. Resource-use efficiency of paddy cultivation in

Peechi Command Area of Thrissur District of Kerala: An economic analysis. Agricultural Economics Research Review, 19 (JanuaryJune): 159-171.

TOB. 2020. 2019 Yılı Hububat sektör raporu. Toprak Mahsulleri Ofisi Genel Müdürlüğü. $44 \mathrm{~s}$.

(erişim:https://www.tmo.gov.tr/Upload/Document /sektorraporlari/hububat2019.pdf 27.04.2021).

TOB, 2019.Tarım Ürünleri Piyasaları-Çeltik. Tarım ve Orman Bakanlığı, Tarımsal Ekonomi ve Politika Geliştirme Enstitüsü Yayınları, Ocak,2019. Ürün No:05, Ankara ( erişim: https://arastirma.tarimorman.gov.tr/tepge/ Belgeler/PDF\%20Tar\%C4\%B1m\%20\%C3\%9C r\%C3\%BCnleri\%20Piyasalar\%C4\%B1/2019Ocak\%20Tar\%C4\%B1m\%20\%C3\%9Cr\%C3\%B Cnleri\%20Raporu/2019-

Ocak\%20\%C3\%87eltik.pdf, 05.10.2020).

TÜiK, 2019. Veritabanı/Tarım/Bitkisel Üretim İstatistikleri. (tahıllar üretim bilgileri). (erişim:

https://biruni.tuik.gov.tr/medas/?kn=92\&lo cale $=$ tr, 05.05.2019).

Vural, H., Turhan, Ş. 2011. Bursa ilinde Şeftali Üretiminin Ekonometrik Analizi. U. Ü. Zir. Fak.Derg, 25 (2): 1-6.

Yamane, T. 2010.Temel örnekleme yöntemleri. Literatür Yayınları (çev. A.Esin). İstanbul, $528 \mathrm{~s}$. 
Yılmaz, S., Yurdakul, O. 2000. İkinci ürün tarımının Aşağı Ceyhan Ovası'ndaki işletmelerin faaliyetleri üzerine etkileri. Çukurova Ün. Zir. Fak. Derg, 15 (1): 39-48.

Yumnam, A., Kumar, A., Chauhan, S.K. 2017. Comparative Economics of Rice Cultivation in Himachal Pradesh and Manipur States of India. Indian Journal of Hill Farming, 30 (2): 227-232.
Zoral, K. 1973. Cobb-Douglas Üretim fonksiyonunun Yukarı Pasinler Ovası'ndaki patates üretimine uygulanması. Atatürk Ün. Yay. No:303, Sevinç Matbaası, Ankara.102 s.

Zoral, K. 1984. Üretim fonksiyonları. Dokuz Eylül Ün. Müh.-Mim. Fak. Yay. (MM/END-84 EY 052), İzmir. 